\title{
Title: Psychosocial care for cancer survivors: a systematic literature review on the role of General Practitioners
}

\section{Short running title: Psychosocial care for cancer survivors by the GP}

Laura Deckx ${ }^{1}$, Ka Hei Chow ${ }^{1}$, Deborah Askew ${ }^{1}$, Mieke L van Driel ${ }^{1}$, Geoffrey K Mitchell ${ }^{1}$, Marjan van den Akker ${ }^{2,3,4}$

\footnotetext{
${ }^{1}$ Primary Care Clinical Unit, Faculty of Medicine, The University of Queensland, Brisbane, Australia

${ }^{2}$ Institute of General Practice, Goethe University, Frankfurt am Main, Germany

${ }^{3}$ Academic Centre for General Practice, KU Leuven, Leuven, Belgium

${ }^{4}$ Department of General Practice, Maastricht University, Maastricht, the Netherlands
}

This article has been accepted for publication and undergone full peer review but has not been through the copyediting, typesetting, pagination and proofreading process, which may lead to differences between this version and the Version of Record. Please cite this article as doi: 10.1002/pon.5612.

This article is protected by copyright. All rights reserved. 


\section{Abstract}

Objective: To explore the GP's role in providing psychosocial care for cancer survivors through a systematic literature review.

Methods: We searched Medline, Embase, PsycINFO, and CINAHL and included studies that complied with the predefined in- and exclusion criteria. At least two independent reviewers performed the quality appraisal and data extraction.

Results: We included 33 studies (5 qualitative, 19 observational, 9 intervention), the majority of which focussed on care for depression and anxiety (21/33). Cancer survivors were more likely to contact their GP for psychosocial problems compared to non-cancer controls. Survivors were more likely to use antidepressants compared to controls, although $71 \%$ of survivors preferred depression treatment to be 'talking therapy only'. Overall, GPs and patients mostly agreed that GPs are the preferred healthcare provider to manage psychosocial problems. The major exception is a survivor's fear of recurrence - here, the oncologist was the preferred healthcare provider. Only two interventions effectively decreased depression or anxiety, these studies included patients who had a clinical indication for psychosocial care, were specifically designed for decreasing depression/anxiety, and consisted of a multidisciplinary team approach. The other interventions evaluated GP-led follow-up for cancer survivors and found that this did not impact the patients' levels of anxiety, depression, or distress neither negatively nor positively.

Conclusions: Cancer survivors often prefer psychosocial care by their GP, and GPs generally consider they are well-placed to provide this care. Although evidence on the effectiveness of psychosocial care by GPs is limited, an active multidisciplinary team approach seems key.

Keywords: Cancer; Oncology; Cancer Survivors; General Practice; Mental Health; Neoplasms; Psychosocial

This article is protected by copyright. All rights reserved. 


\section{Background}

Care needs might be very different for people one year past cancer diagnosis compared to those still in the first acute treatment phase. In the beginning, cancer patients need to adapt to the diagnosis, the uncertainty, the treatment, and its side effects. During this first phase, patients often focus on the physical aspects of having cancer. It is often only when the focus on the physical decreases, that psychological issues first manifest ${ }^{1}$. Studies have shown increasing levels of depression, fear of recurrence and distress after primary cancer treatment has ended ${ }^{2,3}$. It is known that the transition from secondary to primary care is associated with increased psychological distress ${ }^{1}$. For example, cancer survivors most commonly reported needing help with psychosocial care during this time ${ }^{4}$. For some, the diagnosis of cancer even initiates a downward spiral of psychological and social impairment ${ }^{5}$. This downward spiral is the result of an individual's coping response to their cancer experience, which is defined by the interaction between cancer stress and burden such as physical, financial, existential and interpersonal burden and the resources available to that individual ${ }^{5}$. It is therefore not surprising that in the first year after cancer diagnosis, but also several years later, prevalence of depression, anxiety and distress remain high, ranging between $5 \%-50 \%$ for depression, $3 \%-43 \%$ for anxiety, and $4 \%-12 \%$ for distress ${ }^{5,6}$. As cancer survivors transition to primary care, general practitioners (GPs) resume their role as the first point of contact and will have a key role in the provision of psychosocial care for cancer survivors.

Psychological interventions have been shown to successfully reduce depression, anxiety and distress in cancer survivors ${ }^{7-9}$. Nevertheless, despite primary care being an important partner in psychosocial care $^{10}$, psychosocial interventions have mainly been developed in the hospital setting without actively involving the GP. There are numerous trials and systematic literature reviews on psychosocial interventions in cancer patients; for example a Medline search yielded 758 reviews related to psychosocial interventions and cancer, yet none of the reviews described the active role GPs can play (see Appendix 1). This seems like an enormous missed opportunity as the GP is often the first point of contact, especially in countries where the GP plays a gatekeeping role and patients can thus only access additional mental health services such as a psychologist or psychiatrist after referral from a GP.

Therefore, we aimed to systematically review the literature on the role of the GP in providing psychosocial care for cancer survivors across three domains:

1) Explore the services that are being provided by GPs in relation to psychosocial care (e.g. number of visits and drugs or non-pharmaceutical treatments prescribed) for cancer survivors

This article is protected by copyright. All rights reserved. 
2) Explore the views of cancer survivors and healthcare professionals on who should provide psychosocial care

3) Explore the effectiveness of GP-led psychosocial interventions for cancer survivors

This article is protected by copyright. All rights reserved. 


\section{Methods}

This systematic review was registered in the PROSPERO database (CRD42019106356), we followed the PRISMA statement for reporting ${ }^{11}$.

Information sources and search strategy

Medline, Embase, PsycINFO, and CINAHL databases were searched for articles published before the $5^{\text {th }}$ of August 2019. Although we use the term GP throughout the manuscript, we also searched for synonyms such as family practitioner, primary care provider or physician. The search was based on combinations of database-specific subject headings (see Appendix 2. Search strategy). Reference lists of included studies were hand searched and experts in the field were contacted to identify additional studies.

Eligibility criteria and study selection

Any primary research that addressed our aim and research questions were included. Hence, we included qualitative studies, observational quantitative studies, and intervention studies. We focused on the most commonly reported psychosocial problems as found in our own research and literature ${ }^{2,3,12}$ : depression, anxiety, distress, loneliness and fear of recurrence. Other inclusion criteria were: patients diagnosed with invasive cancer; treated with curative intent (excluding palliative care as care needs at the end of life are likely to be different); $\geq 18$ years (excluding adult survivors of childhood cancer); cancer survivors. $\geq 6$ months after cancer diagnosis; reports on the role of the GP or primary care provider in providing care; and written in English.

Studies were screened and selected by at least two researchers independently (LD, KHC, MvdA), researchers were blind to each other's decisions. In cases of disagreement, a decision was reached by consensus.

The quality of included studies was assessed using the following quality assessment tools: The Cochrane risk of bias tool for intervention studies ${ }^{13}$, the National Institutes of Health Quality Assessment Tool for Observational Cohort and Cross-Sectional Studies ${ }^{14}$, and the Hawker checklist for qualitative studies ${ }^{15}$.

Data collection

Data extraction and quality assessment was also done by at least two independent researchers (LD, KHC, MvdA, DA). The reviewers independently extracted data from the articles included in this review into a standardized template. Extracted data considered five domains; 1) study design, 2) objective of the study, 3) characteristics of the participants (number of included participants, mean age, age range, gender, and type of participants, time since cancer diagnosis, response rate), 4) inand exclusion criteria, 5 ) any results related to the role of GPs in providing psychosocial care for

This article is protected by copyright. All rights reserved. 
cancer survivors (number of GP visits, number of referrals, drugs or non-pharmaceutical treatments prescribed, associations between visits and prescriptions, quantitative and qualitative data underpinning the views of cancer survivors and healthcare professionals on who should provide psychosocial care, effect measures of interventions). Where data were unclear or missing, authors were contacted to provide more information. Areas of discrepancy were resolved in group discussions.

In the tables reporting results we used the synonyms for "GPs" as reported in the original paper (e.g. if the word primary care provider was used we kept this as such in the table), however for consistency, we only used the word GP in the manuscript. We also included information on the healthcare system based on an international profiles of health care systems report ${ }^{16}$.

Analyses

Given the large heterogeneity between studies we were not able to pool any data. Instead, we provided a narrative synthesis of the findings from the included studies. We analysed the findings according to our three research questions: 1) What services are being provided (number of GP visits, drugs or non-pharmaceutical treatments prescribed, referrals)?; 2) Who should provide care?; and 3) Which GP-led interventions are effective?

We also performed subgroup analyses to assess the importance of the healthcare system by comparing countries in which GPs have a gatekeeping role compared to those where GPs generally do not have a gatekeeping role; to assess the importance of the type of cancer; and to assess the importance of the type of intervention.

This article is protected by copyright. All rights reserved. 


\section{Results}

\section{Results of the search}

We identified 6354 unique records, we excluded 6049 records based on title and abstract. The full text of the remaining 305 articles was screened by at least two investigators independently. We included 33 studies (see Figure 1. Prisma flow chart): 5 qualitative studies ${ }^{17-21}, 19$ observational studies $^{22-40}$ and 9 intervention studies ${ }^{41-49}$.

The majority of included studies were of good quality (21/33). All qualitative studies were of good quality (see Appendix 3). Two studies scored good on all aspects of the Hawker checklist for qualitative studies ${ }^{18,21}$, for two studies the relationship between researchers and participants was not adequately considered ${ }^{17,20}$, and for one study the analysis framework was insufficiently described ${ }^{19}$.

For the observational studies, 9 were of good quality $26,27,29,30,33-35,39$, three were rated to be of fair quality because the study population was not clearly specified and no sample size or power calculation was provided ${ }^{24}$, the participation rate and loss to follow-up were not reported ${ }^{31}$, or because no multivariate analyses were performed and as a consequence key confounding were not adjusted for $^{32}$ (see Appendix 4). Seven observational studies were rated to be of poor quality because the following criteria were not met or not reported;

- participation rate $<50 \%{ }^{22,23,25,28}$

- $\quad$ sample size or power calculation $22,28,36,37$

- clearly defined exposure measures ${ }^{36,37,40}$

- clearly defined dependent variables ${ }^{40}$

- $\quad$ adjustment for key confounders $22,28,36,37,40$

- $\quad$ blinded outcome assessors ${ }^{23,25}$

- loss to follow-up was $\leq 20 \%^{23,25}$

The majority of intervention studies were of good quality $(7 / 9 \text {, see Appendix } 5)^{42-46,48,49}$. One study was rated to be of fair quality because criteria for allocation concealment and blinding of participants and personnel were not met ${ }^{47}$. One pilot study was rated to be of poor quality because it was a small $(n=9)$ uncontrolled study ${ }^{41}$.

- Figure 1 here -

This article is protected by copyright. All rights reserved. 
The majority of studies (21/33) discussed depression and anxiety $19,20,22,23,26-31,34,35,40,41,43-49$. Five studies discussed distress ${ }^{18,21,24,42,43}$ and six studies discussed fear of recurrence ${ }^{17,33,36-39}$. None of the studies discussed loneliness. The majority of studies were conducted in the UK $(10 / 33)^{18-20,22,28,}$ $29,35,47-49$ or in the US $(9 / 33)^{21,23,25,26,30,34,38,40,46}$, the rest of the studies were conducted in Canada $(5 / 33)^{31,36,37,42,45}$, the Netherlands $(4 / 33)^{17,24,27,41}$, Australia $(4 / 33)$ and Denmark $(1 / 33)^{33}$. Although major differences in primary healthcare between these countries exist, in all these countries except the US, the GP functions as a gatekeeper.

All findings are summarized in a table included in Appendix 6 (Summary of included studies), below follows a narrative summary.

- Table 1 here -

\section{What services are being provided?}

1.1 Number of GP-visits

a. Anxiety and depression

Patients often go to the GP to talk about anxiety and depression. In an observational cohort study ( $N=26,213$; good quality) Khan et al. found that approximately $9 \%$ of breast and prostate cancer survivors, and $8 \%$ of colorectal cancer survivors saw their GP at least once in relation to depression ${ }^{29}$. Another study, based on a cross-sectional survey in a general practice patient population ( $N=9,640$ of which 133 were cancer survivors; poor quality) showed that the higher the depression scores, the higher the proportion of patients who talked to their GP about depression, but the statistical significance of this result was not reported ${ }^{22}$.

Two observational studies showed that cancer survivors with depression have more visits to their GP compared to cancer patients without depression ( $N=680$ cancer patients, including 83 with depression; fair quality; relative risk $=2.35 ; 95 \% \mathrm{Cl} 1.18$ to 4.66$)^{31}$ and also compared to patients without cancer ( $\mathrm{N}=2246$; good quality; incidence rate ratio $1.6 ; 95 \% \mathrm{Cl} 1.4$ to 2.0$)^{27}$.

\section{b. Distress}

Similarly to depression, a study using a cross-sectional survey among 1444 survivors of lymphoma and chronic lymphocytic leukaemia (fair quality) showed that distressed cancer patients were more likely to contact their GP than non-distressed patients ( 5.2 contacts vs 3.3 contacts, respectively; $\mathrm{P}<0.001)^{24}$.

This article is protected by copyright. All rights reserved. 


\section{c. Fear of recurrence}

Fear of recurrence was a significant predictor for more unscheduled GP visits (adjusted regression coefficient $=9.9 ; 95 \% \mathrm{Cl} 2.3$ to 17.4$)$ whereas it was not associated with unscheduled visits to the oncologist (adjusted regression coefficient $=3.9 ; 95 \% \mathrm{Cl}-4.8$ to 12.5 ) in a cross-sectional study among 218 breast cancer survivors (good quality) ${ }^{39}$. Mikkelsen et al. found in a cross-sectional survey study ( $N=353$; good quality) that $20 \%$ of cancer survivors would discuss fear of recurrence with their GP whereas $22 \%$ would discuss this with hospital staff ${ }^{33}$. Having low confidence in the GPs' professional competence and judgement was a significant predictor for not contacting the GP (prevalence ratio $=2.12 ; 95 \% \mathrm{Cl} 1.02$ to 4.42$)^{33}$.

\subsection{Drugs and non-pharmacological treatments prescribed}

\section{d. Anxiety and depression}

Sharpe et al. found in a cross-sectional questionnaire study among 150 cancer survivors with Major Depressive Disorder (MDD) (good quality) that $27 \%$ of patients were prescribed antidepressants by their GP, of which $82 \%$ took the medication ${ }^{35}$. Another retrospective cohort study among 1,673 elderly cancer survivors diagnosed with primary breast, colorectal or prostate cancer and newly diagnosed depression showed that cancer survivors with a high number of GP visits were more likely to use psychotherapy (poor quality, $\mathrm{OR}=1.02 ; 95 \% \mathrm{Cl} 1.00$ to 1.04$)^{23}$. Khan et al. (observational cohort study; $N=26,213$; good quality) showed that breast cancer and prostate cancer survivors were prescribed significantly more antidepressants compared to non-cancer controls $\left(\mathrm{OR}_{\text {breast cancer }}=\right.$ $1.16,95 \% \mathrm{Cl} 1.11$ to $1.22 ; \mathrm{OR}_{\text {prostate cancer }}=1.38,95 \% \mathrm{Cl} 1.25$ to 1.54$)^{29}$.

In an observational quantitative study among 100 cancer survivors with MDD (poor quality), Hodges et al. found that $71 \%$ of patients think that the treatment for depression should be talking therapy only, whereas only $33 \%$ of GPs agreed with this; $67 \%$ of GPs thought that depression should be treated by drug therapy and talking therapy combined, whereas only $26 \%$ of patients agreed with this ${ }^{28}$.

\subsection{Referrals}

\section{e. Anxiety and depression}

Mackenzie et al. showed in a cross-sectional survey study ( $N=145$; fair quality) that $66 \%$ of patients indicated they would accept a referral from their GP to mental health services, $21 \%$ said they would not accept a referral and $13 \%$ were unsure ${ }^{32}$. Sharpe et al. (cross-sectional questionnaire; $N=150$ survivors with MDD; good quality) found that $7 \%$ of patients with MDD were referred to mental health services by their $\mathrm{GP}^{35}$. Of these, 4 patients saw a psychologist, 3 patients saw a psychiatrist and 4 patients did not attend for their appointment ${ }^{35}$. Similarly, Klabunde et al. found in a crosssectional survey study (good quality) among 1,694 GPs and 1,621 oncologists that the majority of

This article is protected by copyright. All rights reserved. 
GPs were involved themselves in assessing/treating depression and only 4\% of GPs reported to refer patients or not being involved in treatment and evaluation of depression, compared to $50 \%$ of oncologists $^{30}$.

\section{Who should provide care?}

\section{f. Anxiety and depression}

GPs reported being actively involved in the assessment and treatment of depression. Klabunde et al. ( $N=1,694$ GPs and 1,621 oncologists; good quality) found that $96 \%$ of GPs reported involvement in the care for depression in cancer survivors ${ }^{30}$. Hodges et al. ( $N=100$ patients with MDD; poor quality) reported $50 \%$ of GPs thought they should treat depression in cancer survivors and $57 \%$ believed it should happen at the GP office ${ }^{28}$.

Similarly, many studies confirm that patients often prefer their GP as the first contact for depression although estimates differ considerably. Mackenzie et al. ( $\mathrm{N}=145$; fair quality) found that $92 \%$ of cancer survivors prefer discussing depression and anxiety with their $\mathrm{GP}^{32}$, Mosher et al. ( $\mathrm{N}=165$; good quality) found that $75 \%$ of lung cancer survivors would prefer to talk to their $\mathrm{GP}^{34}$, whereas Hodges et al. ( $N=100$ patients with MDD; poor quality) found that only $38 \%$ of cancer survivors thought that the GP should treat depression and $47 \%$ of patients thought that this should happen within the GP offices ${ }^{28}$. Interestingly, this UK-study showed that $30 \%$ of patients thought depression care should be provided by a cancer nurse, $26 \%$ by a counsellor (experts in broad areas of mental health), and $4 \%$ by a psychologist (compared to a counsellor they have additional training and education on certain aspects of mental health) and overall $40 \%$ of patients thought that depression treatment should happen at the cancer centre ${ }^{28}$. Zhou et al. ( $\mathrm{N}=615$; poor quality) showed that $33 \%$ of prostate cancer survivors preferred a conversation with their GP as their first choice for information on depression and anxiety, followed by information on a website (25\%), written information sheet (24\%), a phone call from a professional counsellor (9\%), and a conversation with an oncologist $(8 \%)^{40}$.

Two quantitative studies provided insight into which patients preferred to talk to their GP and showed that they were generally older ( $\mathrm{N}=100$ patients with MDD; poor quality; $\mathrm{P}=0.012)^{28}$, did not have health insurance (OR=0.19;95\% $\mathrm{Cl} 0.04$ to 0.99$)$, had lower levels of education (OR=0.80;95\% Cl 0.70 to 0.92 ), and lower income ( $\mathrm{OR}=0.77 ; 95 \% \mathrm{Cl} 0.59$ to 1.00 ) ( $\mathrm{N}=165$ lung cancer patients; good quality) ${ }^{34}$. Levels of depression and anxiety were not associated with the preference to talk to the $\mathrm{GP}^{34}$.

This article is protected by copyright. All rights reserved. 
When comparing views of GPs and oncologists a study among 1,130 oncologists and 1,021 GPs (good quality) showed that $55 \%$ of oncologists believe that they share the responsibility compared with $30 \%$ of $\mathrm{GPs}^{26}$. About $62 \%$ of GPs believe they provide care or referral for depression and anxiety whereas only $11 \%$ of oncologists believe this is the case ${ }^{26}$. Confirming the GPs' view that managing depression and anxiety is mainly their role, a qualitative focus group study among GPs, practice nurses, breast care nurse specialists, oncologists, surgeons and patients (good quality) showed that "GPs are in a better place to cope with anxious patients (quote oncologist)"19.

\section{g. Distress}

Similar to depression, a qualitative study (good quality) among ten early stage colorectal cancer patients, eight oncologists, and six GPs found that all believed that providing support for psychological distress is an important role of the $\mathrm{GP}^{21}$. In another qualitative study among seven GPs (good quality), the patient's psychological distress and its assessment thereof was conceptualised as "a baton which was metaphorically passed from one healthcare professional to the other throughout the patient's cancer journey". Yet, concern was expressed that the baton could be dropped because of poor communication and lack of role clarity. For example, GPs felt that secondary care clinicians were often not part of assessing the patients' distress and were poor at communicating about patient distress with the $G \mathrm{P}^{18}$.

\section{h. Fear of recurrence}

Although fear of recurrence is associated with more unscheduled GP visits, patients do not necessarily seem to prefer care by the GP for fear of recurrence. Smith et al. showed in a crosssectional survey study among 2,107 cancer survivors (good quality) that patients with higher fear of cancer recurrence were less likely to prefer GP-led cancer follow-up care compared to shared care $(\mathrm{OR}=0.96,95 \% \mathrm{Cl}=0.93 \text { to } 0.98)^{38}$. In another observational study ( $\mathrm{N}=1065$ breast cancer survivors; 587 GPs; poor quality), Smith et al. showed that $23 \%$ of breast cancer survivors and only $3 \%$ of GPs had low confidence in the GPs' ability to manage anxiety about fear of recurrence ${ }^{36}$. In contrast to these quantitative studies, one qualitative study among 22 colorectal cancer patients (good quality) showed that fear of recurrence was one of the reasons for colorectal cancer survivors to contact their GP, patients felt that the GP has a reassuring role $^{17}$.

\section{Which GP-led interventions are effective?}

\section{i. Anxiety and depression}

Three intervention studies specifically aimed to treat depression ${ }^{41,48,49}$. Sharpe et al. conducted a multicentre randomised controlled trial (RCT) in 500 cancer survivors with depression (good quality).

This article is protected by copyright. All rights reserved. 
They randomised patients to usual care (provided by a GP) or a specifically designed an intervention delivered by a multidisciplinary team that comprises cancer nurses, a supervising consultationliaison psychiatrist working in collaboration with the patient's oncology team and GP. The study found that depression improved in $62 \%$ of patients in the intervention group, compared to only $17 \%$ of patients in the control group (OR 8.5; 95\% $\mathrm{Cl} 5.5$ to 13.4; $p<0.0001)^{48}$. The same intervention was adjusted for lung cancer patients ( $N=142$; good quality) and again, average depression severity was significantly lower in the intervention group compared to the control group (standardised mean difference $-0.62 ; 95 \% \mathrm{Cl}-0.94$ to -0.29$)^{49}$. The study by Beumeler et al. was a pilot study that evaluated a lifestyle intervention guided by a physical therapist that also included appointments with a dietician and the patient's GP with nine cancer survivors with decreased levels of physical or mental wellbeing (low quality). After 12 months, levels of anxiety had decreased but not depression (anxiety: -0.9; $p=0.011$; depression: $-0.3 ; p=0.395)^{41}$. However, these results were based on nine cancer survivors only and the study did not include a control group ${ }^{41}$.

Five intervention studies tested the effect of GP-led cancer survivorship follow-up ( $N=968$ breast cancer survivors; good quality ${ }^{45} \& \mathrm{~N}=338$ colorectal cancer survivors; good quality ${ }^{44} \& \mathrm{~N}=142$ melanoma cancer survivors; fair quality $\left.{ }^{47}\right)$, of which two included a survivorship care plan ( $N=79$ breast cancer survivors; good quality ${ }^{46} \& \mathrm{~N}=88$ prostate cancer survivors; good quality ${ }^{43}$ ). None of these studies found any significant or clinically relevant differences in anxiety or depression scores compared to usual care ${ }^{43,45-47}$, or compared to follow-up by the surgeon ${ }^{44}$. Although these intervention studies measured the effect of GP-led follow-upon depression and anxiety scores, it was not the objective of these studies to improve anxiety of depression. The objective of the study by Grunfeld et al. for example was 'to test whether follow-up by the patients' GP is a safe and acceptable alternative to specialist follow-up' ${ }^{\prime 45}$.

\section{j. Distress}

GP-led cancer survivorship follow-up does not seem to improve nor worsen levels of distress. One RCT in 408 breast cancer survivors tested if a GP-led survivorship care plan improved outcomes (good quality) and the study found no effect on distress compared to the control group (without a survivorship care plan) $)^{42}$. Similarly, Emery et al. who aimed to test the feasibility of a multifaceted model of shared care showed that shared care with the GP and a survivorship care plan did not result in significant or clinically relevant differences in distress scores in prostate cancer survivors compared to usual follow-up by the hospital ( $N=88$ prostate cancer survivors; good quality) $)^{43}$.

This article is protected by copyright. All rights reserved. 


\section{Subgroup analyses}

1. Healthcare system

Only nine studies were conducted in countries where the GP generally does not have a gatekeeping role. We found that results were similar compared to countries where GPs have a gatekeeping role; in both type of healthcare systems cancer survivors had more drug prescriptions ${ }^{23}$, management of psychosocial problems was seen as an important role of $\mathrm{GPs}^{21,26,30}$, patients often prefer to talk to their GP compared to other healthcare providers ${ }^{34,40}$ - except for fear of recurrence ${ }^{38}$, and interventions that included follow-up by the GP using a cancer survivorship care plan did not impact positively or negatively on depression scores ${ }^{46}$.

2. Type of cancer

Given the large heterogeneity of studies and study populations we were unable to clearly assess the impact of cancer type. For example, the intervention studies that evaluated the effectiveness of GPled follow-up for cancer survivors included breast, prostate, colorectal and melanoma skin cancer patients ${ }^{42-47}$, all of which came to similar conclusions. Similarly, the two intervention studies that were specifically designed to lower depression were conducted in a sample of various cancer types (breast, gynaecological, genitourinary, other $)^{48}$ and a sample of lung cancer patients ${ }^{49}$, the effects of both studies were similar.

3. Type of interventions

Interventions that were specifically designed to address psychosocial problems in cancer survivors with relevant clinical indicators and that were delivered by multidisciplinary teams were effective at decreasing levels of anxiety and depression ${ }^{41,48,49}$. The other intervention studies, which evaluated the effectiveness of GP-led follow-up for cancer survivors did not impact negatively nor positively on the levels of anxiety, depression or distress ${ }^{42-47}$.

This article is protected by copyright. All rights reserved. 


\section{Discussion}

Cancer survivors contact their GP frequently for psychosocial problems and most GPs see themselves as well-placed to provide psychosocial care for cancer survivors. Despite primary care being an important partner in psychosocial care ${ }^{10}$, only 33 studies met the broad inclusion criteria for this review. This is in stark contrast to the existing 758 reviews related to psychosocial interventions and cancer (see Appendix 1). As such, good quality evidence on how the GP can be involved in psychosocial care for cancer survivors is limited. Of the 33 included studies, only nine were intervention studies and interventions in only two studies effectively decreased anxiety or depression. These two studies included patients with a clinical indication for psychosocial care, were specifically designed for this purpose, and consisted of a multidisciplinary team approach. Interestingly, none of the studies that met the inclusion criteria described how GPs actually approached psychosocial care in their clinical practice. For example, do they use a systematic approach by using screening tests and are the screening tests appropriate for cancer survivors? Schouten et al. found that the majority of healthcare professionals (including GPs) does not use a systematic approach to discuss patients' psychosocial concerns, 38\% use the general question "How are you?" and 65\% spontaneously address various psychosocial aspects ${ }^{50}$. Similarly, Geelen et al. found that Dutch GPs generally do not classify cancer survivors as patients that require 'special' care and expect that patients will express their concerns and ask for help ${ }^{51}$. Although GPs generally feel that they pay enough attention to the psychosocial well-being of cancer survivors, previous research has shown that they do not always make good estimates about their patients' psychosocial needs ${ }^{10}$ nor their patients' attitudes towards treatment ${ }^{52}$. More active screening for psychosocial problems has been suggested as one solution ${ }^{10}$ - provided that it is followed by an active treatment plan whereas others suggest that we do not need to identify more cases of psychosocial problems in primary care, but rather, increase the effectiveness of how psychosocial problems are managed ${ }^{53}$. We tend to agree with the latter - provided that the GP has indeed built a good rapport with their patient. In the absence of a good rapport with the healthcare provider, psychosocial problems are often missed and screening is warranted. A two-stage screening approach - with a short screening instrument first, followed by a clinical interview only for high scoring patients - is a feasible approach in practice ${ }^{35}$.

However, identification is only a starting point as an appropriate response is equally as important. In this review we found that cancer survivors were more likely to receive medication for psychosocial problems, but we were unable to assess if patients received a therapeutic dose. Sharpe et al. found that $85 \%$ of cancer patients with MDD - for whom drug-therapy was indicated - were not receiving any appropriate evidence-based treatment; patients either did not take the drugs, or the dosages at

This article is protected by copyright. All rights reserved. 
which they were prescribed were too low to be therapeutically effective ${ }^{35}$. Similarly, merely notifying GPs of their patients' depression diagnosis, increased antidepressant prescription, but it did not improve outcomes ${ }^{48}$. This is not surprising as others found that drug adherence was low and referrals were not always followed-up ${ }^{35}$. It is also not surprising that the effectiveness of antidepressants was limited as it is known that tailored multidisciplinary psychosocial interventions are much more effective ${ }^{54-58}$. Unfortunately, we found little evidence on how psychosocial problems in cancer survivors can be effectively managed in general practice. The only effective interventions were targeted at patients with a clinical indication for psychosocial care, were specifically designed for this purpose, and consisted of a multidisciplinary team approach. This is in line with another review on psychosocial interventions in cancer survivors ${ }^{7}$. In this review also different types of interventions were compared, for example relaxation, psychoeducation, psychotherapy, cognitive behavioural therapy. Interestingly, meta-analyses on these subgroups showed only a significant effect for studies that focused on relaxation and psychoeducation ${ }^{7}$. In contrast, the studies in our review that significantly improved depression/anxiety focused on problem-solving therapy and behavioural activation ${ }^{48,49}$. Nevertheless, there are numerous evidence-based interventions for psychosocial problems, regardless the type of intervention used, the fact that there is a clinical indication and that a multidisciplinary team approach is used are the more defining factors for success $^{54-58}$.

Although treatment for psychosocial problems might be equally as effective when initiated from the hospital setting rather than general practice, the consistent finding that patients prefer their GP as a first point of contact for psychosocial care ${ }^{59,60}$, and the fact that the GP is more accessible justifies more efforts in this space. Further adding to the importance of improving psychosocial care in general practice is the increasing tendency to shift survivorship care to primary care instead of secondary hospital care ${ }^{61,62}$.

There are numerous models of care that involve general practice (or primary care) in cancer survivorship care. Some examples include multidisciplinary survivorship clinics, a community generalist model, or shared-care ${ }^{62}$. As the evidence on the different models is limited and it is unlikely that one size fits-all, a risk-stratification approach has been proposed. This means that depending on a person's risks for cancer-related complications and long-term effects, a mostly oncology, shared care, or mostly general practice based care is chosen ${ }^{62}$. Regardless the model, the role of general practice in survivorship care will increase. For any of the survivorship care models to be effective there needs to be a clear pathway of communication between the oncologist and the $\mathrm{GP}^{62}$. This is perhaps one of the biggest challenges as it is a well-known problem reported across all stages of the care continuum. Survivorship care plans might serve as a tool to facilitate care

This article is protected by copyright. All rights reserved. 
coordination and communication between different healthcare providers. Although there is little evidence that survivorship care plans improve health outcomes, they do have positive effects on for example the amount of information received and satisfaction with care ${ }^{63}$. As most survivorship care plans include a psychosocial component they might also serve as an organisational feature for cancer survivors and could form a link between the oncologist and GP - also for psychosocial care ${ }^{64}$.

\section{Study limitations}

This study has several strengths. It is the first review to give an overview of the GP's role in providing psychosocial care for cancer survivors and it followed a robust and replicable methodology; we published our protocol in PROSPERO in advance, we followed the Prisma statement, and assessed the quality of all included studies. Nevertheless, this study is not without limitations. The heterogeneity of study designs and reporting prevented any pooling of results across studies. Important insights into the role of GPs were not available. For example, cancer survivors preferred to speak to their oncologist about their fears of recurrence of the cancer because of the oncologists' expertise, but preferred to talk to their GP about depression, anxiety, and distress. Unfortunately, no studies provided any insight into why this was so. Furthermore, this review focused on the role of GPs (including family and primary care physicians) but did not consider the full breadth of primary care. For example, we excluded several intervention studies, such as intervention studies focussing on survivorship care plans, because they did not include an active role for the GP, but instead were nurse-led. Last but not least, none of the included studies focused on loneliness, whereas previous studies have repeatedly shown that this is a common and important concern for cancer survivors. ${ }^{65-}$

${ }^{68}$ An observational cohort study showed for example that $42 \%$ of older cancer survivors were feeling lonely one year after cancer diagnosis. ${ }^{3}$ The lack of studies addressing this issue only illustrates that more efforts are needed to address loneliness in cancer survivors.

\section{Clinical implications}

These findings have implications for practice and research. Psychosocial care for cancer survivors by the GP appears feasible and desirable; patients generally prefer to see their GP for psychosocial issues, GPs are easily accessible, and GPs see themselves as well placed to manage psychosocial problems. However, most treatment programs for cancer survivors do not actively include the GP in their approach, and only a few successful studies were identified ${ }^{41,48,49}$. Therefore, more efforts should be made to support GPs in effectively identifying and managing psychosocial problems in cancer survivors. Key elements of successful psychosocial care are an active multidisciplinary team approach with frequent and open communication between all healthcare providers involved (GP, nurse, oncologist, psychologist, psychiatrist), the use of evidence-based interventions, and making sure that if drugs are used, that they are taken at a therapeutic dose.

This article is protected by copyright. All rights reserved. 


\section{Conclusions}

With the exception of fear of recurrence, most cancer survivors prefer to speak to their GP about psychosocial problems rather than other healthcare professionals. GPs generally see themselves as well-placed to provide psychosocial care for cancer survivors. Nevertheless, there seems to be a mismatch between what patients want and what GPs believe is more effective: patients often prefer talking therapy only, whereas most GPs prefer a combination of 'talking' and medication ${ }^{28}$. Therefore, more good quality evidence on how the GP can effectively provide multidisciplinary accessible (non-drug) psychosocial care in the community is necessary to better address the psychosocial care needs of cancer survivors.

This article is protected by copyright. All rights reserved. 


\section{Acknowledgements}

The researchers gratefully acknowledge the Primary Care Collaborative Cancer Clinical Trials Group (PC4) for their support of this project.

Author contributions: LD, KHC, DA and MVDA critically appraised the studies and collected the data; All authors discussed the results and contributed to the final manuscript.

\section{Conflict of interest statement}

The authors have no conflict of interest to report.

\section{Ethics approval}

This research does not require approval by an ethical committee because it is a literature review.

\section{Data availability statement}

Data sharing is not applicable to this article as no new data were created or analysed in this study.

This article is protected by copyright. All rights reserved. 


\section{References}

1. Institute of Medicine. From Cancer Patient to Cancer Survivor: Lost in Transition. Hewitt M, Greenfield S, Stovall E, editors. Washington, DC: The National Academies Press; 2005.

2. Deckx L, van Abbema DL, van den Akker M, van den Broeke C, van Driel $M$, Bulens $P$, et al. A cohort study on the evolution of psychosocial problems in older patients with breast or colorectal cancer: comparison with younger cancer patients and older primary care patients without cancer. BMC Geriatr 2015;15(1):79.

3. Deckx L, van den Akker M, van Driel M, Bulens P, van Abbema D, Tjan-Heijnen V, et al. Loneliness in patients with cancer: the first year after cancer diagnosis. Psycho-Oncology 2015;24(11):1521-8.

4. Lisy K, Langdon L, Piper A, Jefford M. Identifying the most prevalent unmet needs of cancer survivors in Australia: A systematic review. Asia Pac J Clin Oncol 2019.

5. Stein KD, Syrjala KL, Andrykowski MA. Physical and psychological long-term and late effects of cancer. Cancer 2008;112(11 Suppl):2577-92.

6. Brandenbarg D, Maass S, Geerse OP, Stegmann ME, Handberg C, Schroevers MJ, et al. A systematic review on the prevalence of symptoms of depression, anxiety and distress in long-term cancer survivors: Implications for primary care. Eur J Cancer Care 2019;28(3):e13086.

7. Sanjida S, McPhail SM, Shaw J, Couper J, Kissane D, Price MA, et al. Are psychological interventions effective on anxiety in cancer patients? A systematic review and meta-analyses. Psycho-Oncology 2018;27(9):2063-76.

8. Cillessen L, Johannsen M, Speckens AEM, Zachariae R. Mindfulness-based interventions for psychological and physical health outcomes in cancer patients and survivors: A systematic review and meta-analysis of randomized controlled trials. Psycho-Oncology 2019;28(12):2257-69.

9. Xiao F, Song X, Chen Q, Dai Y, Xu R, Qiu C, et al. Effectiveness of Psychological Interventions on Depression in Patients After Breast Cancer Surgery: A Meta-analysis of Randomized Controlled Trials. Clin Breast Cancer 2017;17(3):171-9.

10. Mitchell AJ, Vahabzadeh A, Magruder K. Screening for distress and depression in cancer settings: 10 lessons from 40 years of primary-care research. Psycho-Oncology 2011;20(6):572-84.

11. Moher D, Liberati A, Tetzlaff J, Altman DG, Group P. Preferred reporting items for systematic reviews and meta-analyses: the PRISMA statement. BMJ 2009;339:b2535.

12. Recklitis CJ, Syrjala KL. Provision of integrated psychosocial services for cancer survivors post-treatment. Lancet Oncol 2017;18(1):e39-e50.

13. Higgins JPT, Thomas J, Chandler J, Cumpston M, Li T, Page MJ, et al. Cochrane Handbook for Systematic Reviews of Interventions version 6.0 (updated July 2019): Cochrane; 2019 [Available from: www.training.cochrane.org/handbook.

14. National Institutes of Health. Quality Assessment Tool for Observational Cohort and CrossSectional Studies [02/07/2020]. Available from: https://www.nhlbi.nih.gov/health-topics/studyquality-assessment-tools.

This article is protected by copyright. All rights reserved. 
15. Hawker S, Payne S, Kerr C, Hardey M, Powell J. Appraising the evidence: reviewing disparate data systematically. Qual Health Res 2002;12(9):1284-99.

16. Mossialos E, Djordjevic A, Osborn R, Sarnak D. International Profile of Health Care Systems. New York: Commonwealth Fund; 2017.

17. Brandenbarg D, Roorda C, Stadlander M, de Bock GH, Berger MY, Berendsen AJ. Patients' views on general practitioners' role during treatment and follow-up of colorectal cancer: a qualitative study. Fam Pract 2017;34(2):234-8.

18. Carolan CM, Campbell K. General practitioners' 'lived experience' of assessing psychological distress in cancer patients: an exploratory qualitative study. Eur J Cancer Care 2016;25(3):391-401.

19. Jiwa M, Thompson J, Coleman R, Reed M. Breast cancer follow-up: could primary care be the right venue? Curr Med Res Opin 2006;22(4):625-30.

20. Khan NF, Evans J, Rose PW. A qualitative study of unmet needs and interactions with primary care among cancer survivors. Br J Cancer 2011;105 Suppl 1:S46-51.

21. Sada YH, Street RL, Jr., Singh H, Shada RE, Naik AD. Primary care and communication in shared cancer care: a qualitative study. Am J Manag Care 2011;17(4):259-65.

22. Allgar VL, Neal RD, Pascoe SW. Cancer patients consultation patterns in primary care and levels of psychological morbidity: findings from the Health Survey for England. Psycho-Oncology 2003;12(7):736-40.

23. Alwhaibi M, Madhavan S, Bias T, Kelly K, Walkup J, Sambamoorthi U. Depression Treatment Among Elderly Medicare Beneficiaries With Incident Cases of Cancer and Newly Diagnosed Depression. Psychiatr Serv 2017;68(5):482-9.

24. Arts LPJ, Oerlemans S, Tick L, Koster A, Roerdink HTJ, van de Poll-Franse LV. More frequent use of health care services among distressed compared with nondistressed survivors of lymphoma and chronic lymphocytic leukemia: Results from the population-based PROFILES registry. Cancer 2018;124(14):3016-24.

25. Bowman KF, Rose JH, Deimling GT, Kypriotakis G, O'Toole EE. Primary care physicians' involvement in the cancer care of older long-term survivors. J Aging Health 2010;22(5):673-86.

26. Forsythe LP, Alfano CM, Leach CR, Ganz PA, Stefanek ME, Rowland JH. Who provides psychosocial follow-up care for post-treatment cancer survivors? A survey of medical oncologists and primary care physicians. J Clin Oncol 2012;30(23):2897-905.

27. Heins MJ, Korevaar JC, Rijken PM, Schellevis FG. For which health problems do cancer survivors visit their General Practitioner? Eur J Cancer 2013;49(1):211-8.

28. Hodges L, Butcher I, Kleiboer A, McHugh G, Murray G, Walker J, et al. Patient and general practitioner preferences for the treatment of depression in patients with cancer: how, who, and where? J Psychosom Res 2009;67(5):399-402.

29. Khan NF, Ward AM, Watson E, Rose PW. Consulting and prescribing behaviour for anxiety and depression in long-term survivors of cancer in the UK. Eur J Cancer 2010;46(18):3339-44.

This article is protected by copyright. All rights reserved. 
30. Klabunde CN, Ambs A, Keating NL, He Y, Doucette WR, Tisnado D, et al. The role of primary care physicians in cancer care. J Gen Intern Med 2009;24(9):1029-36.

31. Lo C, Calzavara A, Kurdyak P, Barbera L, Shepherd F, Zimmermann C, et al. Depression and use of health care services in patients with advanced cancer. Can Fam Physician 2013;59(3):E168E74.

32. Mackenzie L, Carey M, Sanson-Fisher R, D'Este C, Yoong SL. A cross-sectional study of radiation oncology outpatients' concern about, preferences for, and perceived barriers to discussing anxiety and depression. Psycho-Oncology 2015;24(11):1392-7.

33. Mikkelsen T, Sondergaard J, Sokolowski I, Jensen A, Olesen F. Cancer survivors' rehabilitation needs in a primary health care context. Fam Pract 2009;26(3):221-30.

34. Mosher CE, Winger JG, Hanna N, Jalal SI, Fakiris AJ, Einhorn LH, et al. Barriers to mental health service use and preferences for addressing emotional concerns among lung cancer patients. Psycho-Oncology 2014;23(7):812-9.

35. Sharpe M, Strong V, Allen K, Rush R, Postma K, Tulloh A, et al. Major depression in outpatients attending a regional cancer centre: screening and unmet treatment needs. Br J Cancer 2004;90(2):314-20.

36. Smith SL, Murchison S, Singh-Carlson S, Alexander C, Wai ES. Survivorship care in breast cancer: Perceptions of patients and primary care physicians. Can Fam Physician 2015;61(6):e277e83.

37. Smith SL, Wai ES, Alexander C, Singh-Carlson S. Caring for survivors of breast cancer: perspective of the primary care physician. Curr Oncol 2011;18(5):e218-26.

38. Smith TG, Strollo S, Hu X, Earle CC, Leach CR, Nekhlyudov L. Understanding Long-Term Cancer Survivors' Preferences for Ongoing Medical Care. J Gen Intern Med 2019.

39. Thewes B, Butow P, Bell ML, Beith J, Stuart-Harris R, Grossi M, et al. Fear of cancer recurrence in young women with a history of early-stage breast cancer: a cross-sectional study of prevalence and association with health behaviours. Support Care Cancer 2012;20(11):2651-9.

40. Zhou ES, Bober SL, Nekhlyudov L, Hu JC, Kantoff PW, Recklitis CJ. Physical and emotional health information needs and preferences of long-term prostate cancer survivors. Patient Educ Couns 2016;99(12):2049-54.

41. Beumeler LFE, Waarsenburg EC, Booij SH, Scheurink AJW, Hoenders HJR. Evaluation of a lifestyle intervention program in primary care on physical and mental health and quality of life of cancer survivors: A pilot study. Eur J Integr Med 2018;23:1-5.

42. Boekhout AH, Maunsell E, Pond GR, Julian JA, Coyle D, Levine MN, et al. A survivorship care plan for breast cancer survivors: extended results of a randomized clinical trial. J Cancer Surviv 2015;9(4):683-91.

43. Emery JD, Jefford M, King M, Hayne D, Martin A, Doorey J, et al. ProCare Trial: a phase II randomized controlled trial of shared care for follow-up of men with prostate cancer. BJU Int 2017;119(3):381-9.

This article is protected by copyright. All rights reserved. 
44. Gall CA, Weller D, Esterman A, Pilotto L, McGorm K, Hammett Z, et al. Patient satisfaction and health-related quality of life after treatment for colon cancer. Dis Colon Rectum 2007;50(6):8019.

45. Grunfeld E, Levine MN, Julian JA, Coyle D, Szechtman B, Mirsky D, et al. Randomized trial of long-term follow-up for early-stage breast cancer: a comparison of family physician versus specialist care. J Clin Oncol 2006;24(6):848-55.

46. Kvale EA, Huang CS, Meneses KM, Demark-Wahnefried W, Bae S, Azuero CB, et al. Patientcentered support in the survivorship care transition: Outcomes from the Patient-Owned Survivorship Care Plan Intervention. Cancer 2016;122(20):3232-42.

47. Murchie $P$, Nicolson MC, Hannaford PC, Raja EA, Lee AJ, Campbell NC. Patient satisfaction with GP-led melanoma follow-up: a randomised controlled trial. Br J Cancer 2010;102(10):1447-55.

48. Sharpe M, Walker J, Holm Hansen C, Martin P, Symeonides S, Gourley C, et al. Integrated collaborative care for comorbid major depression in patients with cancer (SMaRT Oncology-2): a multicentre randomised controlled effectiveness trial. Lancet 2014;384(9948):1099-108.

49. Walker J, Hansen CH, Martin P, Symeonides S, Gourley C, Wall L, et al. Integrated collaborative care for major depression comorbid with a poor prognosis cancer (SMaRT Oncology-3): a multicentre randomised controlled trial in patients with lung cancer. Lancet Oncol 2014;15(10):1168-76.

50. Schouten B, Bergs J, Vankrunkelsven P, Hellings J. Healthcare professionals' perspectives on the prevalence, barriers and management of psychosocial issues in cancer care: A mixed methods study. Eur J Cancer Care 2019;28(1):e12936.

51. Geelen E, Krumeich A, Schellevis FG, van den Akker M. General practitioners' perceptions of their role in cancer follow-up care: a qualitative study in the Netherlands. Eur J Gen Pract 2014;20(1):17-24.

52. Kendrick T, King F, Albertella L, Smith PW. GP treatment decisions for patients with depression: an observational study. Br J Gen Pract 2005;55(513):280-6.

53. Kessler D, Sharp D, Lewis G. Screening for depression in primary care. Br J Gen Pract 2005;55(518):659-60.

54. Katon W, Von Korff M, Lin E, Simon G, Walker E, Unutzer J, et al. Stepped collaborative care for primary care patients with persistent symptoms of depression: a randomized trial. Arch Gen Psychiatry 1999;56(12):1109-15.

55. Unutzer J, Katon W, Callahan CM, Williams JW, Jr., Hunkeler E, Harpole L, et al. Collaborative care management of late-life depression in the primary care setting: a randomized controlled trial. JAMA 2002;288(22):2836-45.

56. Katon W, Robinson P, Von Korff M, Lin E, Bush T, Ludman E, et al. A multifaceted intervention to improve treatment of depression in primary care. Arch Gen Psychiatry 1996;53(10):924-32.

57. Gilbody S, Bower P, Fletcher J, Richards D, Sutton AJ. Collaborative care for depression: a cumulative meta-analysis and review of longer-term outcomes. Arch Intern Med 2006;166(21):231421.

This article is protected by copyright. All rights reserved. 
58. Bower P, Gilbody S, Richards D, Fletcher J, Sutton A. Collaborative care for depression in primary care. Making sense of a complex intervention: systematic review and meta-regression. $\mathrm{Br} J$ Psychiatry 2006;189:484-93.

59. Mao JJ, Bowman MA, Stricker CT, DeMichele A, Jacobs L, Chan D, et al. Delivery of survivorship care by primary care physicians: the perspective of breast cancer patients. J Clin Oncol 2009;27(6):933-8.

60. Meiklejohn JA, Mimery A, Martin JH, Bailie R, Garvey G, Walpole ET, et al. The role of the GP in follow-up cancer care: a systematic literature review. J Cancer Surviv 2016;10(6):990-1011.

61. Hewitt M, Greenfield S, Stovall E, editors. From Cancer Patient to Cancer Survivor: Lost in Transition. Washington, DC: Institute of Medicine; 2005.

62. Nekhlyudov L, O'Malley D M, Hudson SV. Integrating primary care providers in the care of cancer survivors: gaps in evidence and future opportunities. Lancet Oncol 2017;18(1):e30-e8.

63. Jacobsen PB, DeRosa AP, Henderson TO, Mayer DK, Moskowitz CS, Paskett ED, et al. Systematic Review of the Impact of Cancer Survivorship Care Plans on Health Outcomes and Health Care Delivery. J Clin Oncol 2018;36(20):2088-100.

64. Jacobsen PB. Clinical practice guidelines for the psychosocial care of cancer survivors: current status and future prospects. Cancer 2009;115(18 Suppl):4419-29.

65. Wells M, Kelly D. The loneliness of cancer. Eur J Oncol Nurs 2008;12(5):410-1.

66. Rosedale M. Survivor loneliness of women following breast cancer. Oncol Nurs Forum 2009;36(2):175-83.

67. Brennan J, Gingell P, Brant $\mathrm{H}$, Hollingworth $\mathrm{W}$. Refinement of the distress management problem list as the basis for a holistic therapeutic conversation among UK patients with cancer. Psychooncology 2012;21(12):1346-56.

68. Tuinman MA, Gazendam-Donofrio SM, Hoekstra-Weebers JE. Screening and referral for psychosocial distress in oncologic practice: use of the Distress Thermometer. Cancer 2008;113(4):870-8.

This article is protected by copyright. All rights reserved. 


\section{Tables}

Table 1. Overview of included studies

\begin{tabular}{|c|c|c|c|}
\hline Type of study & ANXIETY AND DEPRESSION & DISTRESS & FEAR OF RECURRENCE \\
\hline \multirow[t]{2}{*}{ Qualitative study } & Jiwa et al. ${ }^{19}$ & Carolan et al. ${ }^{18}$ & Brandenbarg et al. ${ }^{17}$ \\
\hline & Khan et al. ${ }^{20}$ & Sada et al. ${ }^{21}$ & \\
\hline \multirow[t]{12}{*}{ Observational study } & Allgar et al. ${ }^{22}$ & Arts et al. ${ }^{24}$ & Bowman et al. ${ }^{25}$ \\
\hline & Alwhaibi et al. ${ }^{23}$ & & Mikkelsen et al. ${ }^{33}$ \\
\hline & Forsythe et al. ${ }^{26}$ & & Smith et al. ${ }^{37}$ \\
\hline & Heins et al. ${ }^{27}$ & & Smith et al. ${ }^{36}$ \\
\hline & Hodges et al. ${ }^{28}$ & & Smith et al. ${ }^{38}$ \\
\hline & Khan et al. ${ }^{29}$ & & Thewes et al. ${ }^{39}$ \\
\hline & Klabune et al. ${ }^{30}$ & & \\
\hline & Lo et al. ${ }^{31}$ & & \\
\hline & Mackenzie et al. ${ }^{32}$ & & \\
\hline & Mosher et al. ${ }^{34}$ & & \\
\hline & Sharpe et al. ${ }^{35}$ & & \\
\hline & Zhou et al. ${ }^{40}$ & & \\
\hline \multirow[t]{8}{*}{ Intervention study } & Beumeler et al. ${ }^{41}$ & Boekhout et al. ${ }^{42}$ & \\
\hline & Emery et al. ${ }^{43}$ & Emery et al. ${ }^{43}$ & \\
\hline & Gall et al. ${ }^{44}$ & & \\
\hline & Grunfeld et al. ${ }^{45}$ & & \\
\hline & Kvale et al. ${ }^{46}$ & & \\
\hline & Murchie et al. ${ }^{47}$ & & \\
\hline & Sharpe et al. ${ }^{48}$ & & \\
\hline & Walker et al. ${ }^{49}$ & & \\
\hline
\end{tabular}

This article is protected by copyright. All rights reserved. 


\section{Figures}

Figure 1. PRISMA flow chart

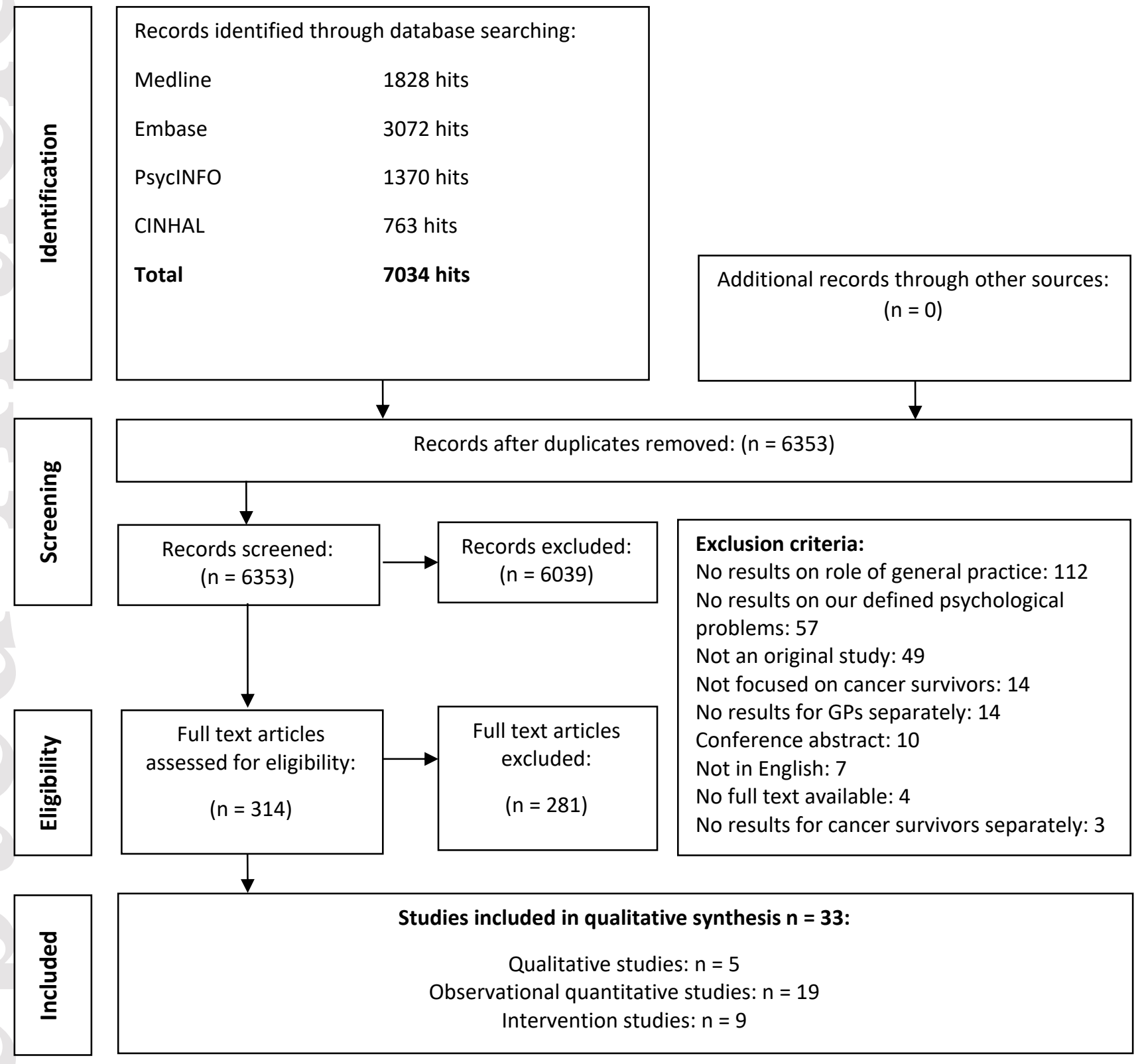

This article is protected by copyright. All rights reserved. 